\title{
An automatic loading system for rock core testing with an industrial CT scanner
}

\author{
Zhao Hong ${ }^{1,2 *}$ and Zhao Yixin ${ }^{2}$ \\ ${ }^{1}$ College of Mechanical and Transpartation Engineering, China University of Petroleum, Beijing 102249, China \\ ${ }^{2}$ State Key Laboratory of Coal Resources and Safe Mining, China University of Mining and Technology, Beijing 100083, China \\ (C) China University of Petroleum (Beijing) and Springer-Verlag Berlin Heidelberg 2011
}

\begin{abstract}
A new type of a loading and measuring system was developed for testing failure and deformation of rock core samples with an industrial CT (ICT) scanner. The loading and measuring system consisted of a loading system and a computer control system. The maximum servo-controlled force was 2 tonnes. The new system was a high-stiffness system with a small size. During ICT tests, rock core samples could be easily loaded in the axial direction. So the initiation, propagation, and coalescence of cracks in core samples were observed on ICT images.
\end{abstract}

Key words: Industrial CT, dynamic loading, automatic loading system, rock core, crack propagation

\section{Introduction}

$\mathrm{X}$-ray computed tomography $(\mathrm{CT})$ is a medical imaging method employing tomography created by computer processing (Herman, 2009). Digital geometry processing is used to generate a three-dimensional (3D) image of the internal structure of an object from a large series of twodimensional (2D) X-ray images taken around a single axis of rotation (Beckmann, 2006). CT produces a volume of data which can be manipulated, through a process known as "windowing", in order to demonstrate various bodily structures based on their ability to block the X-ray beam. Although historically the images generated were in the axial or transverse plane, orthogonal to the long axis of the body, modern scanners allow this volume of data to be reformatted in various planes or even as volumetric (3D) representations of structures. Although most common in medicine, CT is also used in other fields, such as industry, engineering, agriculture and safety testing.

$\mathrm{CT}$ is a nondestructive, fast, and precise technique that is used in the industrial field for metrology in addition to the visual inspection primarily used in the medical CT scan. Medical CT scanners have been used to detect low-density materials, such as rock cores, carbon composite materials, and light alloys (Hofmann et al, 2004). However, its use is limited in bulk materials with high density due to the lowenrgy X-ray source and its low penetration depth. Since the 1980s, special research projects on industrial CT (ICT) have been carried out in the US military. After several decades of research, industrial CT is now being developed towards a quantitative inspection technique, which uses

* Corresponding author. email: hzhao_cn@163.com

Received January 16, 2011 high-energy X-ray equipment to produce 3D representations of components both externally and internally. Industrial CT scanning has been used in many areas of industry for internal inspection of components. Some of the key uses for CT scanning have been flaw detection, failure analysis, metrology, assembly analysis, and reverse engineering applications (Conroy and Vannier 1984; Holler and Kögler 1990; Muzi et al, 2004).

Compared with conventional medical CT scanners, ICT scanners were widely used to study the rock fracture mechanics. ICT can obtain $2 \mathrm{D}$ or $3 \mathrm{D}$ images of test samples, and the space displacement, shape and dimensional information can be obtained from the images directly. Traditional medical CT tests project the three dimensional objects to two-dimensional plates and the images are overprinted. It is hard to detect the precise location and obtain quantitative measurement. ICT has excellent density resolution and some of the high quality images can get $0.3 \%$. It is higher than traditional nondestructive testing. The dynamic response range of the detector is $10^{6}$ which is higher than film and image enhancement.

Several loading systems were designed for ICT scanners with which the rock performance was investigated. Ge et al (1999) designed a triaxial loading cell for the medical CT scanner to provide control of the applied pressure in three principal loading directions and then the faulting in coal samples was observed and recorded with the scanner. Tian et al (2010) developed a dynamic loading apparatus for CT experiments (medical CT) of concrete samples and the initiation, propagation, and coalescence of fractures in the concrete samples observed on CT images. However, these loading systems were specially designed for medical CT scanners, and they were not suitable for ICT scanners due to the limits of the rotation stage. So it is very important to 
design a special loading system mounted on the rotation stage of ICT for measuring the mechanical properties of rock and soil samples.

This work presented here specifically details the design of the configuration of the loading system for ICT and its drive system. A wireless remote control system is used to control the loading system during experiments. Additionally, a main control computer is used to record all real-time loading data.

\section{General configuration of the automatic loading apparatus for ICT}

Industrial CT scanners were widely developed for core analysis and powerful X-ray sources were provided by synchrotron radiation facilities. In geomechanical characterization of rock cores, ICT has been envisaged as an alternative technique able to minimize uncertainties in axial test interpretation. It delivers much useful information on the fracture processes induced in mechanical tests. Effects of preexisting geological features inside samples can be qualitatively assessed and the control of rock core heterogeneity and anisotropy on resulting strength potentially investigated. In order to achieve the above mentioned aims, it was necessary to develop an apparatus with the capability not only of measuring the destructive force but also of showing the relationship with the deformation. In this study, an industrial X-ray computed tomography (ICT) scanner was used as a tool to noninvasively image three dimensional information on core samples during loading.

The CT scans were acquired on an ACTIS 225/320 industrial scanner with a tube voltage of $10-220 \mathrm{kV}$, tube current of $0.01-1.0 \mathrm{~mA}$, spot size of $10 \mu \mathrm{m}$, and the power of $10 \mathrm{~W}$, as shown in Fig. 1. The industrial CT was equipped with a micro-focusing system to achieve a stable spot size and a rotation stage used for test sample rotation. The precision of the scan is $10 \mu \mathrm{m}$.

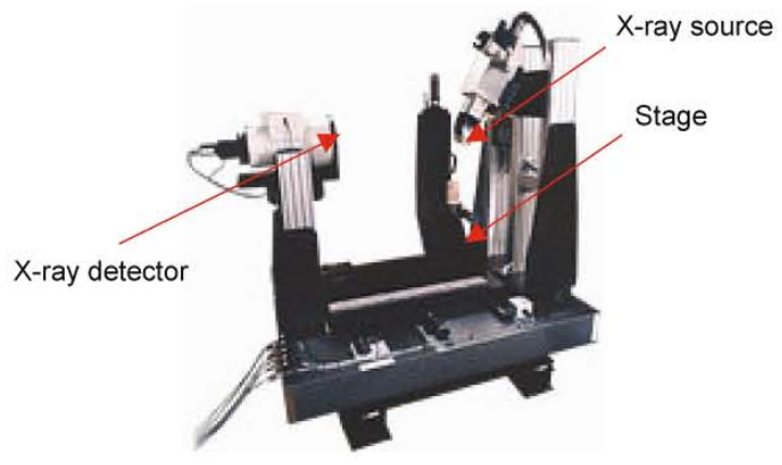

Fig. 1 Illustration of the industrial CT

On the basis of the literature (Dai and Li, 2004; He et al, 2010; Mao et al, 2010), an automatic loading and measuring system for ICT was developed (as shown in Figs. 2 and 3), which consisted of a loading system in the ICT room and a control system in the master-control room to control the loading system and measure the data transferred from the loading system. Fig. 2 shows a schematic of the loading system in the ICT room and Fig. 3 is pictures of the control system in the master-control room.

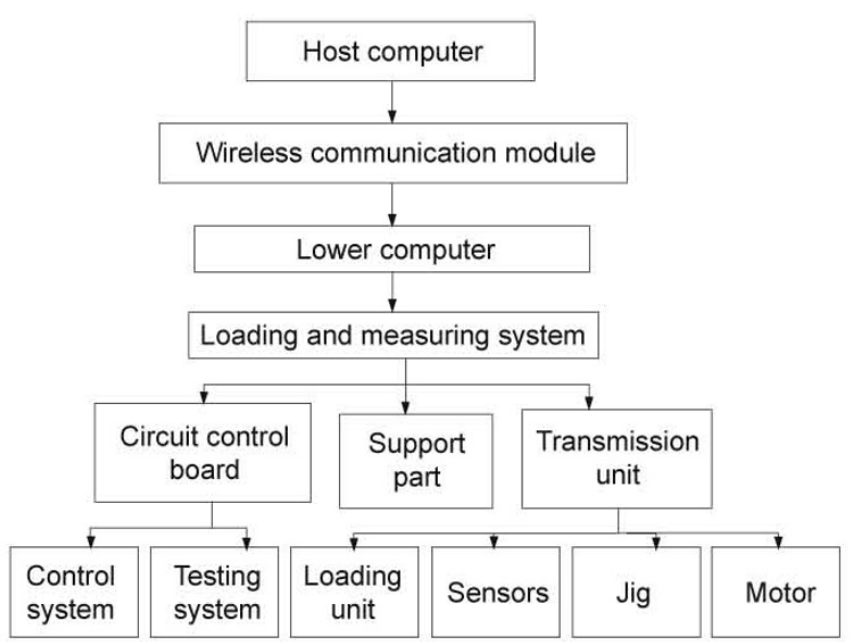

Fig. 2 A schematic of the loading and measuring system

One of the first design decisions that had to be made was the data transfer scheme for the loading apparatus in the ICT room. The wireless communication module is the best choice for the apparatus on the rotation stage of ICT. More specifically this design will automatically control the loading system in the ICT room. With the use of the designed loading system, a rapid and advantageous technique can however be provided for an improved interpretation of axial tests. In particular, critical evidences of axial deformation data on samples can be adequately related to the observed mechanical behavior and mode of deformation.

The loading system in the ICT room included a main framework and a cylindrical vessel. The main framework, $0.14 \mathrm{~m} \times 0.14 \mathrm{~m} \times 0.2 \mathrm{~m}$, is made of high-strength steel and weights $12 \mathrm{~kg}$ (power supply line not included). The vessel is made of acrylic plastic which X-ray can penetrate through and can be easily mounted on and demounted from the top of the main framework. The loading system was also equipped with a mechanical transmission unit. The main feature of the transmission unit on the rotation stage in ICT is that a motor is used to drive a jig to transmit the loading unit to load the desired force. Sensors were installed at various positions of the main framework, for example a force sensor installed at the top of the mechanical transmission unit. The mass distribution and shape of the loading apparatus ensured that the loading force was always centered in the center of the rotation stage. The velocity of the motor was varied to suit the loading force. Compared with the manual loading system, the integrity of the loading system on the rotation stage and the controllability from the master-control room were improved (as shown in Fig. 3). The whole structure on the rotation stage is compact to get the radius of rotation within $15 \mathrm{~cm}$. The price of the new-type loading system is $10 \%$ of the similar equipment from other countries. In addition, the mechanical structure has much space for additional sensors to allow extra functions. The main parameters of the loading system were as follows: maximum velocity in the loading direction was 0.06 $\mathrm{mm} / \mathrm{s}$; maximum distance in the loading direction was 60 $\mathrm{mm}$; maximum axial loading force was $20 \mathrm{kN}$; the power was $210 \mathrm{~W}$. 


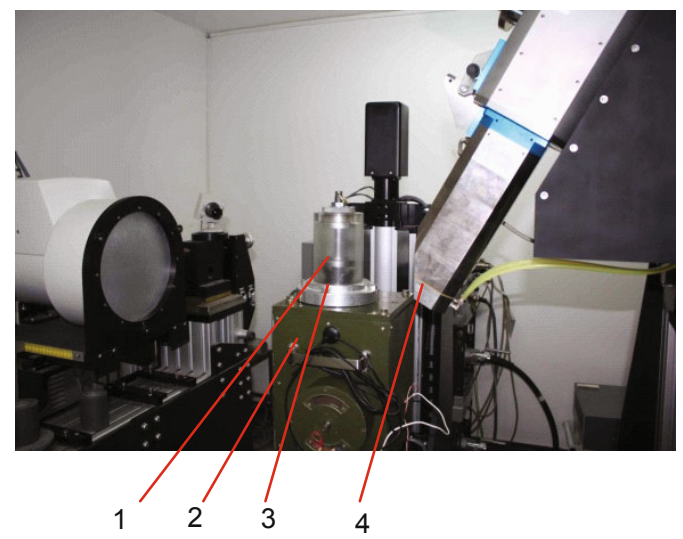

(a) Loading and measuring system

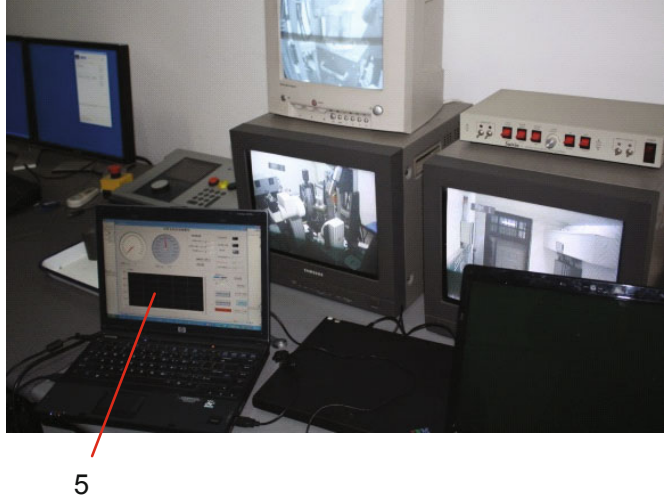

(b) Host computer system

Fig. 3 Structure of the automatic loading apparatus and the control system

1- Sample vessel, 2- Loading apparatus framework, 3- Rock core sample, 4- Industrial CT, 5- Host computer control system

\section{Drive transmission design of the loading system}

A number of power transmission options were examined in order to determine the optimal transmission scheme for design of this automatic loading system. The main criteria in evaluating these different options were the mechanical efficiency of the system from the motor and the limited space on the rotation stage in the ICT. Ge et al (1999) monitored rock deformation by means of medical X-ray CT. Tian et al (2010) developed a dynamic loading and unloading system for medical CT scanners, which was used to investigate concrete failure. EPHL University in Switzerland developed a loading system for medical CT scanners (Viggiani et al, 2004). Another mechanical system for CT scanners was studied in Washington State University (Razavia, 2006). Lenoir et al (2007) designed a loading system for CT with axial loading max $7.5 \mathrm{kN}$ and $\min 1 \mu \mathrm{m} / \mathrm{min}$, the whole equipment was high precision, very complex and expensive. Some research was focused on the hydraulic control system, but this system is unsuitable for the rotation stage in ICT. The gear transmission would allow for the motors to be mounted vertically and offers high gear ratios and help to minimize the width of the system size. The final option is a gear transmission. An 110LY-02 servo motor was used to drive the gear transmission to automate the loading unit. On the manual loading process for ICT, one has to enter and exit the ICT scanner room many times for loading and unloading during ICT scanning. This is time-consuming. Horeover, using the automatic loading and measuring system for ICT, dynamic loading and real-time control are achieved. Of course, during scanning the force remains constant by using a self-looking mechanism.

\section{Control system design of the loading system}

The stage on the ICT is rotary so the power supply for the loading system fixed on the stage is a problem. Therefore a rotary power supply system was designed to solve this problem. The power was supplied with the power line to the loading apparatus on the stage. On the other hand, the designed control system consisted of the host computer in the master-control room and lower embedded system in the loading apparatus in the ICT room. The host computer in the master-control room could control the motor to obtain the dynamic loading force in the ICT room through the wireless signal transmission module to the embedded system. At the same time, all kinds of the signals from the sensors were sent to the host computer and user-friendly software was developed for real-time control. Compared with the manual loading system on ICT, it is convenient to operate the newtype automatic loading system.

\section{Test procedures and results}

The core samples for this apparatus were $\Phi 25 \mathrm{~mm} \times 50 \mathrm{~mm}$, $\Phi 25 \mathrm{~mm} \times 25 \mathrm{~mm}$ or $\Phi 50 \mathrm{~mm} \times 50 \mathrm{~mm}(\Phi 25 \mathrm{~mm} \times 50 \mathrm{~mm}, 25$ $\mathrm{mm}$ in diameter and $50 \mathrm{~mm}$ long). The static and dynamic forces were loaded using the designed loading system during CT scanning. The samples were set in the acrylic plastic vessel which was fixed on the top of the main framework and the loading apparatus was set on the rotation stage in the ICT scanner. The host computer controlled the loading force by communicating with the lower embedded system in the loading apparatus. The ICT scanner generates images which can discriminate the materials' instability and deterioration failure as well as corresponding characteristic of the precursory phenomenon from the interior's images. The samples were loaded in a mechanical testing machine to determine their operating force range before the ICT loading test. The acquired images illustrate by single ICT slices from core sample as shown in Fig. 4. Left views are direct ICT acquired images from the sample that was scanned under a certain loading force. In that case, the images are represented by changing the single-axial force in each of the slices. The ICT images from left to right (as shown in Fig. 4) are the correspondent slices from a scan. Test procedures are that the samples were loaded by changing the single-axial force until the sample were deformed and then by adjusting the loading force and the maximum destruction force of the sample was recorded as shown in Fig. 5. Fig. 5 shows the relations 
between the loading force and the deformation displacement of the samples.

The direct mechanical characterization of rock cores in this research aims to perform a classification according to their mode of deformation. A series of ICT scanning images were obtained under different stresses.

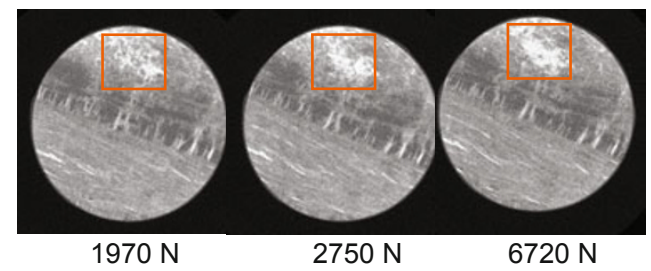

(a) Slice No. 1

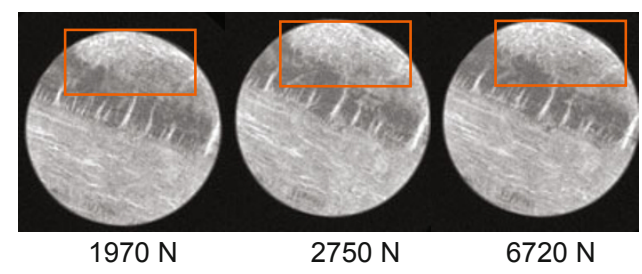

(b) Slice No. 2

Fig. $4 \mathrm{CT}$ images of core samples under different forces

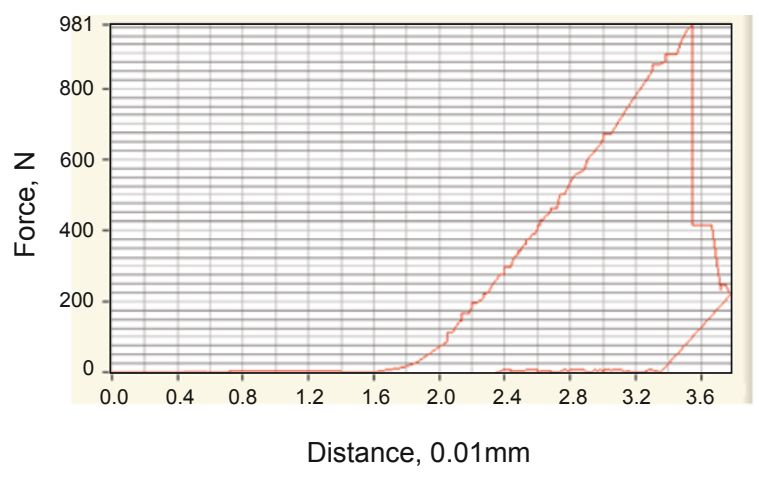

Fig. 5 Curve of force and deformation distance of the coal sample

\section{Conclusions}

The components and features of the designed wireless automatic loading system are introduced in this paper.

1) The designed loading system is robust, low production cost and simple operation compared with manual loading system and some automatic loading systems in the area.

2) The designed loading and measuring system better illustrates axial failure by effectively visualizing rock core deformation and evaluates the amount of damages which present in each rock core and relates them with sample properties. Moreover, this system can automatically record the relation curve of the deformation displacement and loading force.

3) The automatic loading system consists of the software monitor system in the control room and the mechanical system in laboratory. The host computer can process a mass of data from the real-time condition. So it meets the dynamic test requirements for ICT.

\section{Acknowledgements}

The research is financially supported by the National Natural Science Foundation of China (Grant No. 50905186, No. 51174213), the Major State Basic Research Development Program Fund (Grant No. 2010CB226804), the Projectsponsored by SRF for ROCS, the Ministry of Education and Fundamental Research Funds for the Central Universities and Research Program in State Key Laboratory of Coal Resources and Safe Mining of China University of Mining and Technology.

\section{References}

Beckmann E C. CT scanning the early days. The British Journal of Radiology. 2006. 79(January): 5-8

Conroy G C and Vannier M W. Noninvasive three-dimensional computer imaging of matrix-filled fossil skulls by high-resolution computed tomography. Science. 1984. 226: 456-458

Dai G L and Li X H. CT real time testing of meso-failure mechanisms of rock under loading and unloading conditions. Journal of Engineering Geology. 2004. 12(01): 104-108 (in Chinese)

Ge X R, Ren J X, Pu Y B, et al. A real-in-time CT tri-axial testing study of mesa-damage evolution law of coal. Chinese Journal of Rock Mechanics and Engineering. 1999. 18(5): 497-502 (in Chinese)

He M C, Wang C G, Li D J, et al. Desorption characteristics of adsorbed gas in coal samples under coupling temperature and uniaxial compression. Chinese Journal of Rock Mechanics and Engineering. 2010. 29(5): 865-871 (in Chinese)

Herman G T. Fundamentals of Computerized Tomography: Image Reconstruction from Projection (2nd edition). Springer. 2009

Holler P and Kögler F C. Computer tomography: A non-destructive, high-resolution technique for investigation of sedimentary structures. Marine Geology. 1990. 91: 263-266

Hofmann J, Flisch A and Obrist A. Adaptive CT scanning-mesh based optimization methods for industrial X-ray computer tomography applications. NDT \& E International. 2004. (37): 271-278

Lenoir N, Bornert M, Desrues J, et al. Volumetric digital image correlation applied to X-ray micro tomography images from triaxial compression tests on argillaceous rock. Strain. 2007. 43: 193-205

Mao L T, An L Q, Wang Z G, et al. Experimental study of relationship between coal mechanical characteristics and interior crack evolution using CT technique. Journal of Liaoning Technical University (Natural Science). 2010. 29(3): 408-411 (in Chinese)

Muzi L, Lyons A P and Pouliquen E. Use of X-ray computed tomography for the estimation of parameters relevant to the modeling of acoustic scattering from the seafloor. Nuclear Instruments and Methods in Physics Research. 2004. B213: 491497

Razavia M R. Characterization of microstructure and internal displacement field of sand using X-ray computed tomography. Ph.D Dissertation. Washington State University. December, 2006

Tian W, Dang F N, Ding W H, et al. Development of a dynamic loading apparatus for CT experiment and its application. Rock and Soil Mechanics. 2010. 31(1): 309-313 (in Chinese)

Viggiani G, Lenoira N, Bésuellea P, et al. X-ray micro tomography for studying localized deformation in fine-grained geo-materials under tri-axial compression. Comptes Rendus Mécanique. 2004. 332(10): 819-826

(Edited by Sun Yanhua) 